\title{
Recommendations for repairing the facades of the factory building of the "Experienced sports equipment in Moscow"
}

\author{
Victor Kamskov ${ }^{1, *}$ \\ ${ }^{1}$ Moscow State University of Civil Engineering, Yaroslavskoe shosse, 26, 129337, Moscow, Russia
}

\begin{abstract}
The article presents the results of performed visual and instrumental surveys that allow to clarify and expand information on the structural design of the walls of the building, the nature of the damage and the cause of their origin. In order to obtain a more complete initial information on the surveyed object, visual and instrumental surveys were additionally carried out to clarify and expand information on the structural design of the building walls, the nature of the damage and the cause of their origin. Project-technical, executive and acceptance documentation for construction, as well as acts of survey of hidden works on the site are absent. By instrumental methods it is established that there is a gap between the surface of the main wall and the facing brick layer and the deviation of the facing layer from the vertical surface. As a result of inspection of the opened window slopes, it is established that the mesh protruding from the main masonry does not enter the lining seams but is bent into the gap. Therefore, the facing layer of masonry, which is devoid of connection with the main wall, operates independently as a selfsupporting wall. Therefore, it is necessary to fix the facing layer to the laying of the main wall with steel ties. Examination of the facing of the facing layer revealed the presence of damage in the form of cracks having a vertical and horizontal orientation. Based on the results of the survey, recommendations were developed to ensure reliable and safe operation of the building wall structures in close connection with an in-depth analysis of the causes of these damages.
\end{abstract}

\section{Introduction}

Development of recommendations for the elimination of damage to the facing brickwork of the exterior walls of the two-storey administrative and production building of ZAO "Plant of Experienced Sports Technology" is the development of the results of expert assessment of the causes of these damages (Fig. 1). The surveyed building has two floors with a height of about 3 each M., As well as a basement under the building part. In terms of the building, the building is rectangular in shape with dimensions a $x=20.23 \times 25.3 \mathrm{~m}$. The laying of the main walls of a building made of full-bodied ceramic bricks $51 \mathrm{~cm}$ thick was first erected without facing, and after two years the facing was made. To fix and connect

* Corresponding author: kamskov@mail.bg 
the facing layer with the main masonry of the outer walls, a masonry grid was laid in it during the production of the works, the outlets of which were to be included in the cladding of the facing layer $[1,2]$.

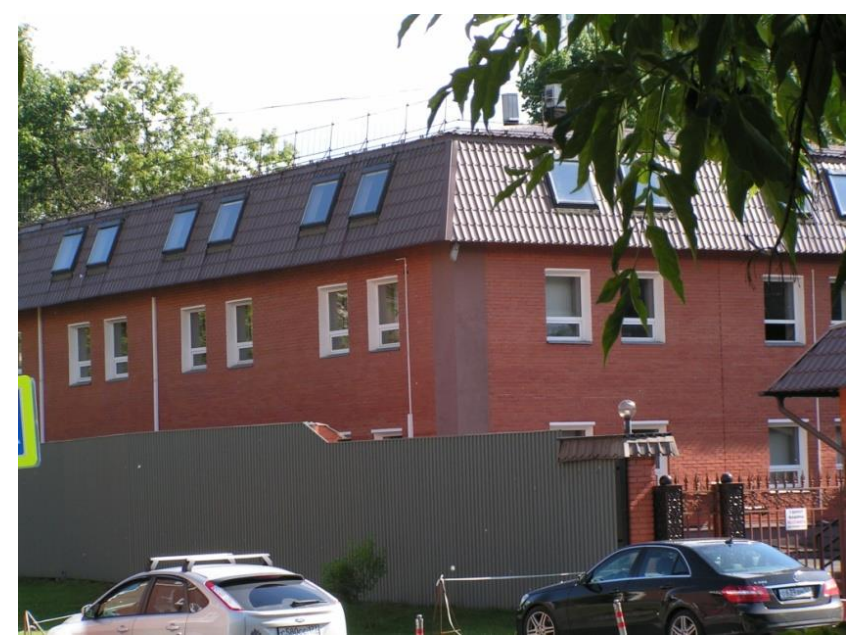

Fig. 1. General view of the renovated building.

To support the facing layer from the bottom of the wall, there is a socle wall made of full-bodied ceramic bricks $25 \mathrm{~cm}$ wide and 60 to $95 \mathrm{~cm}$ high. This wall could not be placed on the edge of the foundation blocks with a width of $60 \mathrm{~cm}$ and the width of the main wall $51 \ldots 52 \mathrm{~cm}$. Therefore, to support the socle wall along the ground, a horizontally located monolithic reinforced concrete beam section $30 \times 30 \mathrm{~cm}$ was concreted. The nature of the reinforcement of this beam is not established. According to its design and operation under load, it is a long flexible beam on an elastic base (Fig. 2).

The laying of the facing layer is made of a Baltic brick with dimensions axBxc = $85 \times 247 \times 64 \mathrm{~cm}$. Due to the fact that the masonry of the main walls was made with vertical deviations (Fig. 2), the gap between the facing layer and the main brickwork is variable from 1.5 to $5 \mathrm{~cm}$, The gap was not filled with a special solution, there are separate random solution inclusions (Fig. 3).

As a result of inspection of the opened window slopes, it is established that the mesh protruding from the main masonry does not enter the lining seams but is bent into the gap. Consequently, the facing layer of masonry, which is devoid of connection with the main wall, works independently as a self-supporting wall $85 \mathrm{~mm}$ thick. And a height of $6000 \mathrm{~mm}$ [3].

The strength of the materials of the facing layer of the masonry, determined by the nondestructive method, corresponds to: for brick grade M100; For solution grade M75.

Design resistance of the masonry. At the accepted initial data, for a brick and a solution according to table 2 of SNiP II-22-8 * "Stone and armo-stone constructions "is assumed to be $\mathrm{Rc}=0.85 \times 17=14 \mathrm{~kg} / \mathrm{cm}^{2}$ [4-9]. 


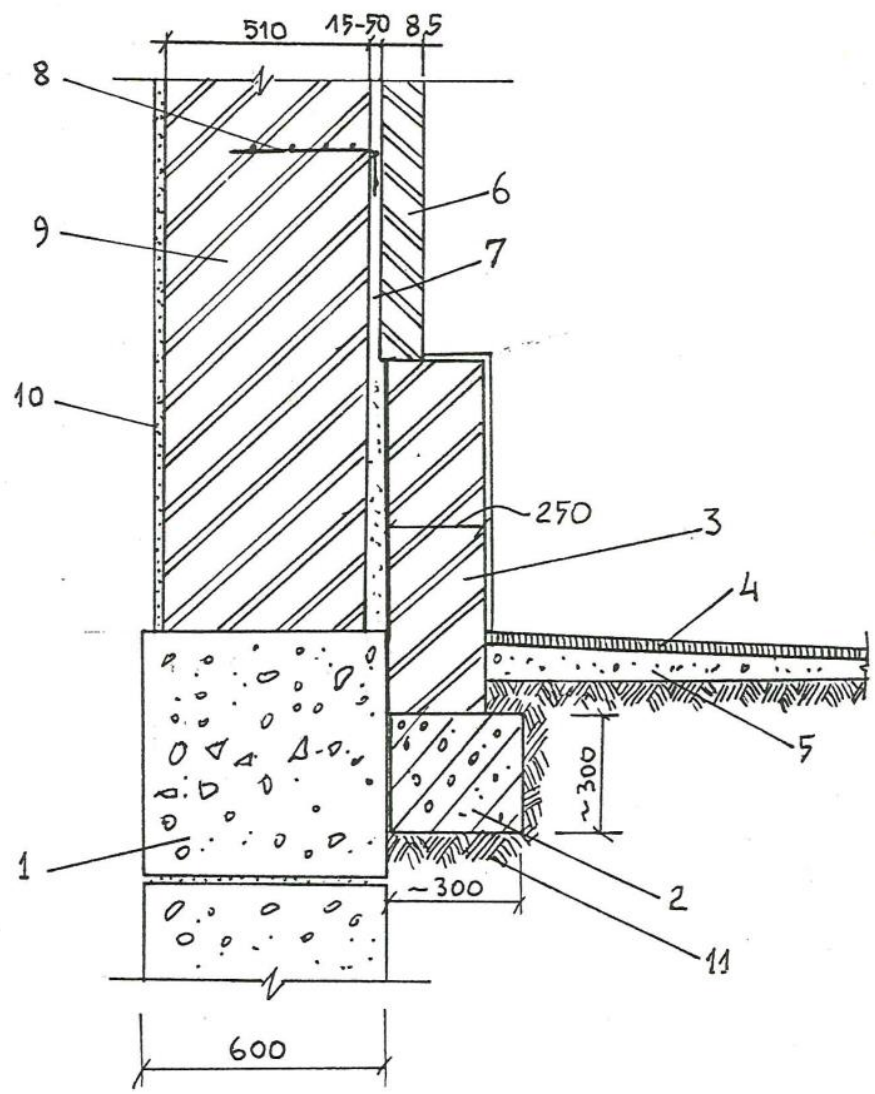

Fig. 2. Schematic diagram of the support of the facing layer and the socle wall in the level of the top of the foundation (6) and (3).

a)

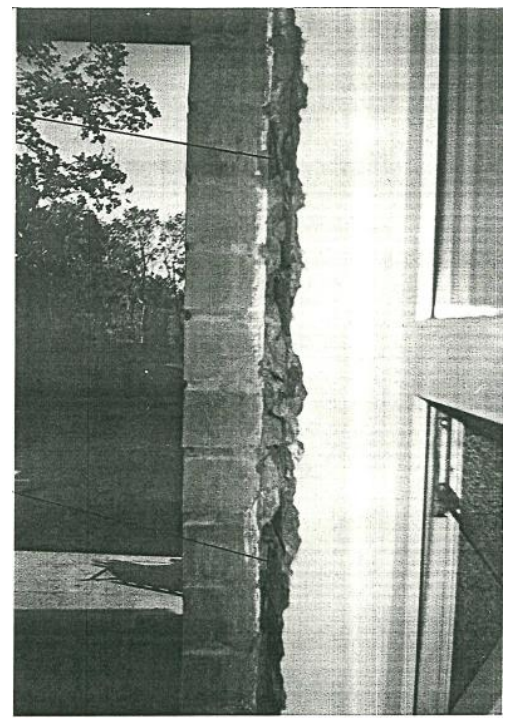

b)

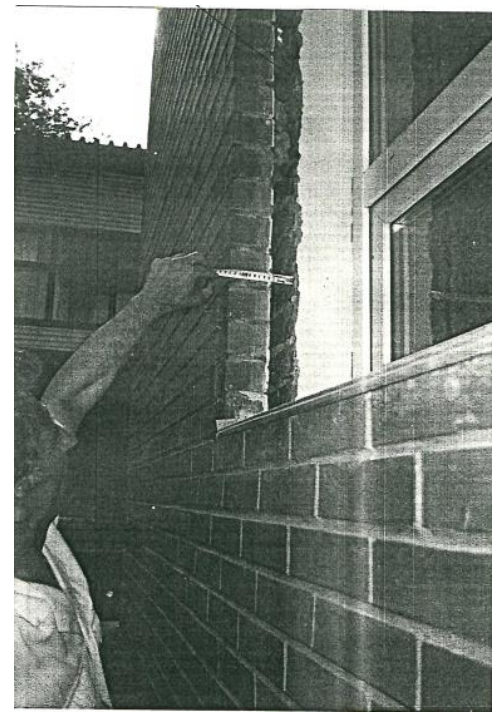

Fig. 3. The width of the open gap along the slope between the facing layer and the main wall (a) is 5 cm. (b). 
Examination of the cladding of the facing layer revealed the presence of damage in the form of cracks having a vertical and horizontal orientation, which are shown in (Fig.4).

a)

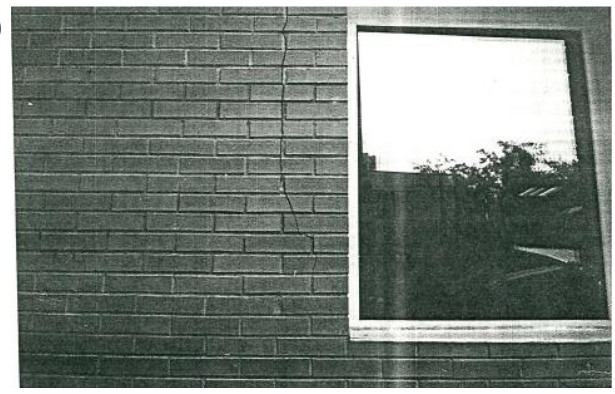

b)

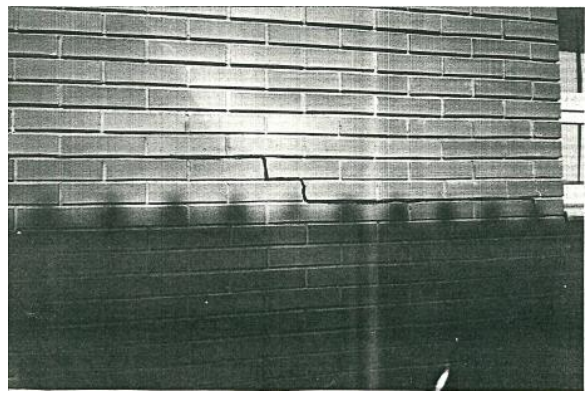

Fig. 4. Vertical a) and horizontal b) cracks in the cladding.

\section{Literature review}

In this work, we use literary sources, whose authors at various times have carried out a significant amount of research work in the field of building materials, materials science, concrete, reinforced concrete and reinforced-stone structures. These include prof. I.A.Rybiev, prof. A.I. Bedov. Prof. E.V. Korolyov. The author of the article for many years cooperated with prof. A. I. Bedov and other teachers of the department of concrete, Reinforced concrete and reinforced-stone constructions of MISI-MGSU, having carried out jointly a considerable number of scientific research works. The author's works are also listed in the list of literature sources, the materials of which were used in the performance of this work.

\section{Materials and methods}

Of the reasons that caused the formation of cracks in the facing, two should be distinguished:

Horizontal cracks:

1. The stressed state of the facing layer when it is subjected to a vertical load of its own weight in the presence of eccentricity due to the deviation of the facing from the vertical at insufficient number of flexible connections between the facing and the main wall;

2. The vertical draft of the socle wall on which the lining rests against the deflections of the reinforced concrete contour beam erected over the loose ground;

Vertical cracks:

1. The stressed state of the facing layer when working on compression from its own weight, as a sign of overstrain of the masonry;

2. The uneven draft of the basement wall with a supporting contour reinforced concrete beam;

3. Efforts of the horizontal direction, caused by temperature deformations of the facing layer, insulated from the main masonry by an air layer and having insufficient number of flexible connections with the main wall [10].

To assess the stressed state of the facing masonry working on eccentric compression, it is necessary to determine the actual eccentricity of the vertical force from the own weight of the masonry. The value of the eccentricity was calculated from the results of measurements of the deviation of the facing from the vertical position by scanning around the perimeter of the entire building in steps of two meters (Fig. 5). 


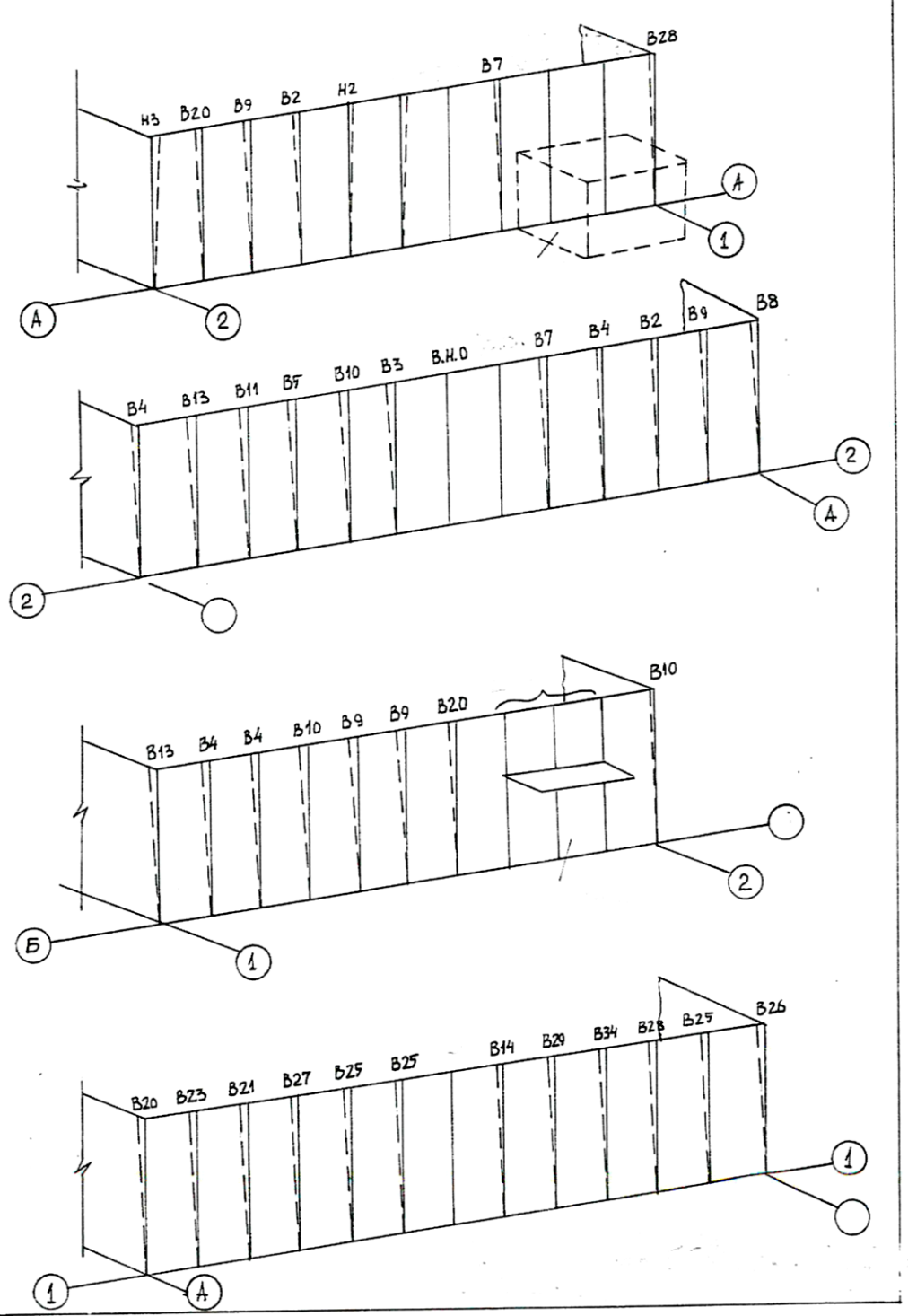

Fig. 5. Results of measuring the deviations of the facing layer of the masonry from the vertical.

The analysis showed that the deviations of the facing layer of the masonry are almost outward, a. In general, there are deviations inward from the main wall, where the deviation varies between $14 \ldots 34 \mathrm{~mm}$. Therefore, for the verification calculation, the masonry section with an average deviation value of $\delta=26 \mathrm{~mm}$ is adopted. The calculation for the eccentric compression of the facing is carried out according to the formula 13 SNiP II 22-81 (Date of update 01.02.2017).

$$
\mathrm{N} \leq \mathrm{mg} * \mathrm{Ac} * \varphi 1 * \mathrm{R} * \omega
$$

Where: $\mathrm{N}$ - the acting design compressive force from the self-weight of the masonry made of hollow ceramic bricks from one p.m. Facing at the base level $\mathrm{N}=\mathrm{b} * \mathrm{~L} * \mathrm{~h} * \rho *$ $\gamma \mathrm{f}=0.085 * 1.00 * 6.1 * 1600 * 1.1=913 \mathrm{~kg} / \mathrm{m} . \mathrm{Ng}=\mathrm{N}=913 \mathrm{~kg} / \mathrm{p} . \mathrm{m}$. 
$\mathrm{R}$ - design resistance of the masonry is equal to $14 \mathrm{~kg} / \mathrm{cm}^{2}$; Ac is the area of the compressed section section of $330 \mathrm{~cm}^{2}$;

$\Omega=1-\eta * \mathrm{Ng} / \mathrm{N}[1+1.2 *$ eo / h $] ; \mathrm{Ng}=\mathrm{N}=913 \mathrm{~kg} / \mathrm{m} ; \mathrm{H}=\mathrm{f}[\lambda, \mu] ; \mathrm{Eo}=2.6 \mathrm{~cm} ; \mathrm{H}$ $=8.5 \mathrm{~cm}$.

If we assume that the connections from the reinforcing mesh that connect the main wall with the facing cladding do not go into it at the entire height of the building, then the calculated length $10=0.75 * 2 \mathrm{H}=0.75 * 12.2=915 \mathrm{~cm}$. Moreover, the flexibility of the lining wall $\lambda=10 / \mathrm{H}=915 / 8.5=107.6$, which significantly exceeds the limit value of flexibility, and the ratio of the height $\mathrm{H}$ to the wall thickness $\mathrm{h} \mathrm{B}=\mathrm{H} / \mathrm{h}=610 / 8.5=$ $71.8>$ the limiting value is $1.8 * 25=45.0$ (Clause $6.17,6.18$ SNiP II-22-81*).

Respectively. With such flexibility, the coefficients $\mathrm{mg}$ and take values close to zero, and the load-bearing capacity of the facing layer also becomes close to zero and clearly insufficient to absorb the force $\mathrm{N}==913 \mathrm{~kg} / \mathrm{pm}$. However. Obvious signs of destruction of the facing layer is not noted. Apparently some of the anchor ties were still used and. Most likely, in the level of overlapping above the basement, the first and second floors. Calculation of the formation and the disclosure of horizontal seams in the facing can not be performed as e $<0.7 \mathrm{y}$, where $\mathrm{e}=2.6 \mathrm{~cm} ; \mathrm{Y}=\mathrm{h} / 2=8.5 / 2=4.25 \mathrm{~cm} .2 .6 / 4.25=0.61$ $<0.7$; L0 $=2.6 \mathrm{~cm} .<0.7 * 4.25=2.98 \mathrm{~cm}$. Thus, the cause of the formation of horizontal step cracks is not the bending stress, but, apparently, the vertical deformation of the socle wall. The local sedimentation of the soil foundation under the contour reinforced concrete girder. Therefore, to avoid the appearance of new horizontal cracks in the facing layer and the development of old ones. It is recommended to transfer the load from the facing layer completely to the main wall by means of the installation of new anchor connections.

When examining the facing areas with vertical cracks, it is established that the edges of the cracks do not have a mutual vertical displacement. This fact allows us to state that vertical cracks were formed not because of uneven sediment of the base. But are caused by the action of horizontally directed forces and deformations. Such forces are caused by temperature-humidity influences on the laying of the facing layer (angular zones). As well as the difference in temperature deformations of longitudinal inclusions in the form of steel overhead lintels for two windows with a length of more than $3.5 \mathrm{~m}$ and the masonry itself. The cladding of the facing layer does not have sufficient reinforcement and its can be considered unreinforced. Such a masonry does not work well on stretching, and therefore, cracks may appear in it with temperature changes. In order to avoid the appearance of cracks. The temperature-shrinkage joints are necessary for temperature-induced deformations. According to clause 6.78 of $\mathrm{SNiP}$ II-22-81*, the temperature-shrinkage seams are arranged in the places of possible concentration of deformations. In this case, the distance between the temperature-shrinkage seams is determined by the calculation and is represented in the form of stress diagrams in (Fig. 6). 
a)

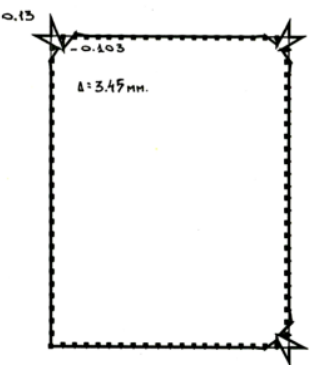

b)

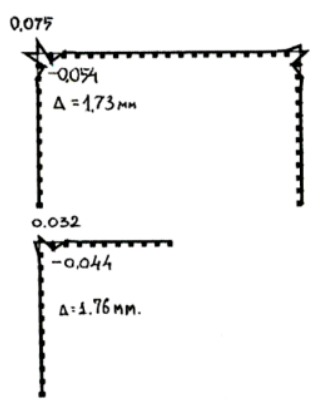

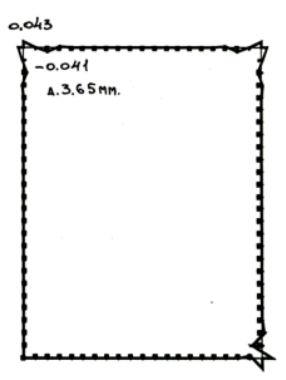
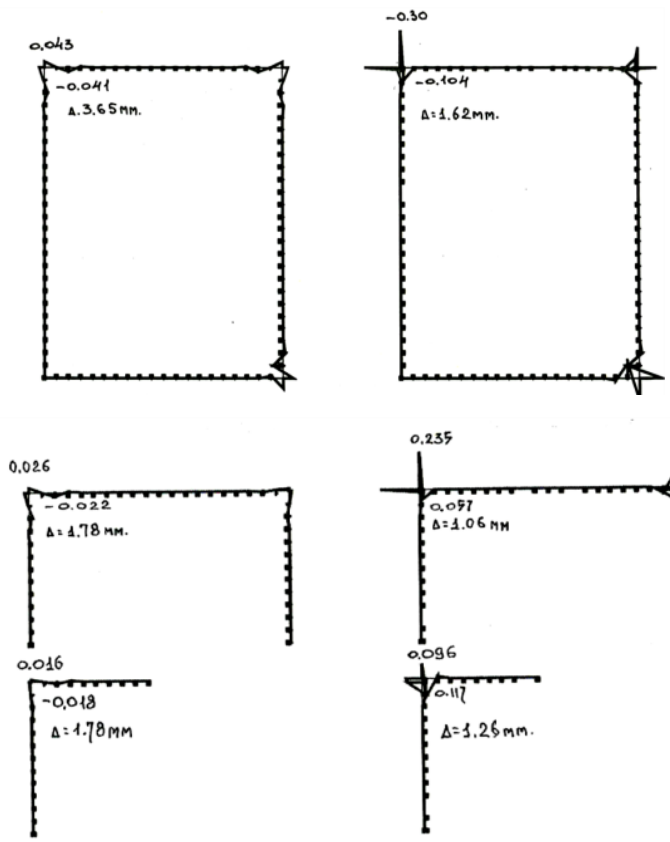

Fig. 6. Diagrams of bending moments in the angular zones of the facing layer in the absence of a) and the presence of deformation beads $b$ ).

\section{Results}

1. It is established that between the surface of the main wall and the facing brick layer there is a gap of $1.5 \ldots 5.0 \mathrm{~cm}$ and a deviation of the facing layer from the vertical surface to 3.5 $\mathrm{cm}$, the gap has not been filled with a special solution, there are separate random inclusions.

2. As a result of inspection of the opened window slopes, it is established that the mesh protruding from the main masonry does not enter the lining seams but is bent into the gap. Consequently, the facing layer of masonry, which is devoid of connection with the main wall, works independently as a self-supporting wall $85 \mathrm{~mm}$ thick. And a height of 6000 $\mathrm{mm}$.

3. The strength of the materials of the facing layer of the masonry, determined by the non-destructive method, corresponds to: for brick grade M100; For solution grade M75. Design resistance of the masonry. With the initial data taken, for brick and mortar according to table 2 of SNiP II-22-8 * "Stone and reinforced stone structures" is taken equal to $\mathrm{Rc}=0.85 \times 17=14 \mathrm{~kg} / \mathrm{cm}^{2}[11]$.

4. It is necessary to fix the facing layer to the laying of the main wall with steel ties. Holes for bonds $\varphi 20 \mathrm{~mm}$. Drilled by an electrified tool. The links are staggered in steps of $50 \ldots 80 \mathrm{~cm}$ from the rods of $\mathrm{f} 10 \ldots 12 \mathrm{~mm}$. Periodic profile, the length of $35 \ldots 40 \mathrm{~cm}$ at an angle of 300 (Fig.7).

5. Examination of the facing of the facing layer revealed the presence of damage in the form of cracks having a vertical and horizontal orientation. 
a)

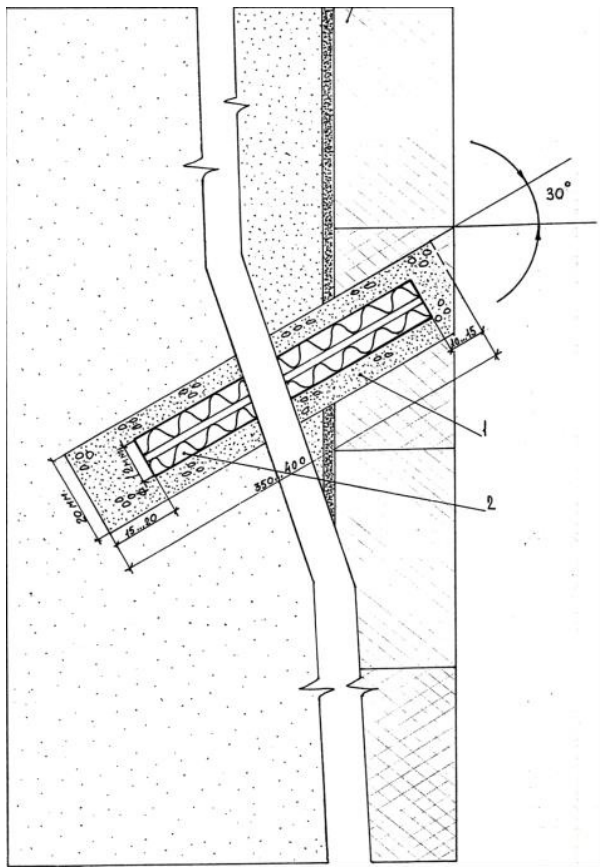

b)

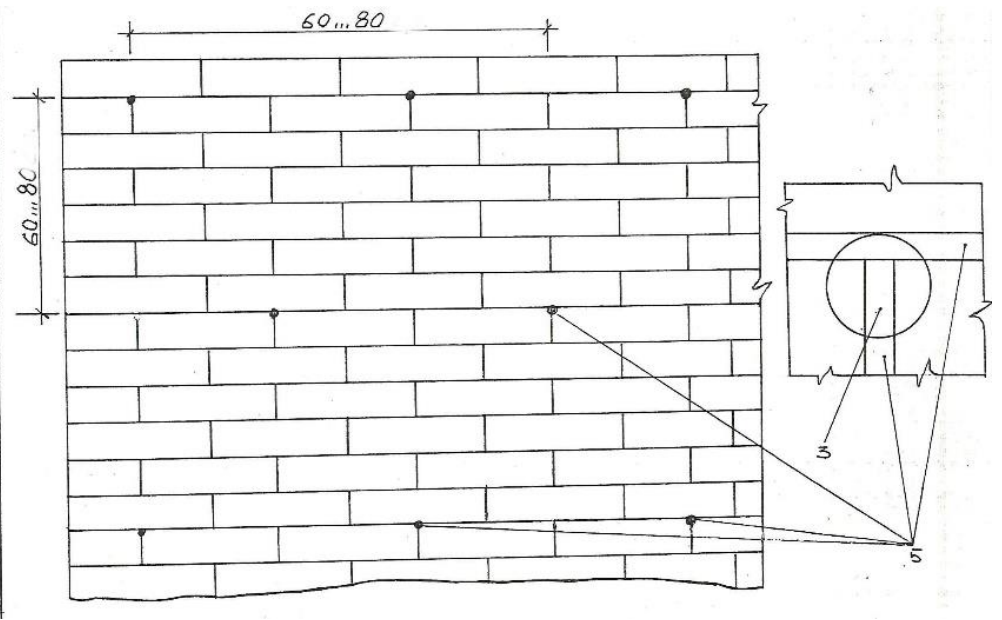

Fig. 7. Fastening the cladding to the wall [a] and the location of the rods [b].

6. The apertures are blown with compressed air and filled with a syringe with a plastic cement-sand paste. Insert the rods into the holes and seal the paste with the subsequent seaming.

7. In 7 days after installation of connections it is recommended to zainzirovat clearances between a laying of the basic wall and facing cement-sandy paste of the same structure, as for steel connections. For injection, one hole is recommended for an area located between two ties and reamed to the depth of the facing brick, that is $85 \mathrm{~mm}$. Fastening of the cladding should be made by grippers of a width of $5 \mathrm{~m}$ and a height of no more than $2 \mathrm{~m}$. [12-14].

8. It is ascertained that on the surface of the facing brick at a distance of up to $60 \mathrm{~cm}$ from the corners vertical vertical vertical cracks were found with the opening $1.5 \quad \ldots 2.0$ $\mathrm{mm}$. To preserve the decorative texture of the brick and eliminate vertical cracks, it is 
proposed to make a plaster coating from a cement-sand mortar $30 \mathrm{~mm}$ thick at the corners of the building. On a metal grid of $\varphi 4 \mathrm{~mm}$. With a cell 50x50 mm. [15-18]. After curing the solution, the surface is puttyed and colored (Fig. 8).

a)
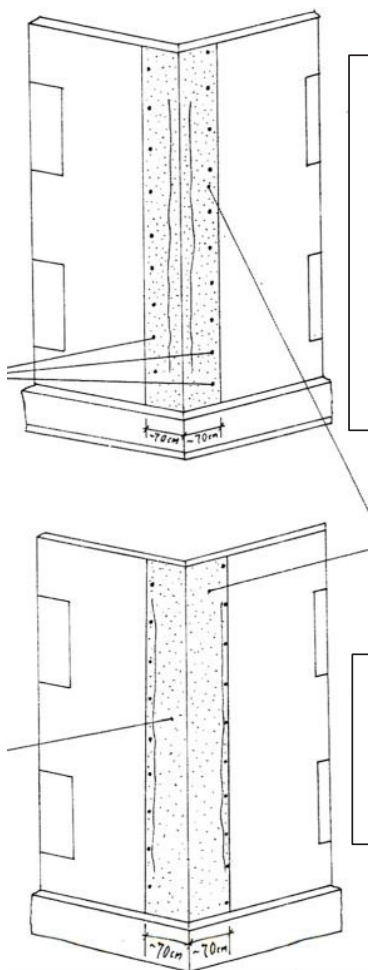

b)

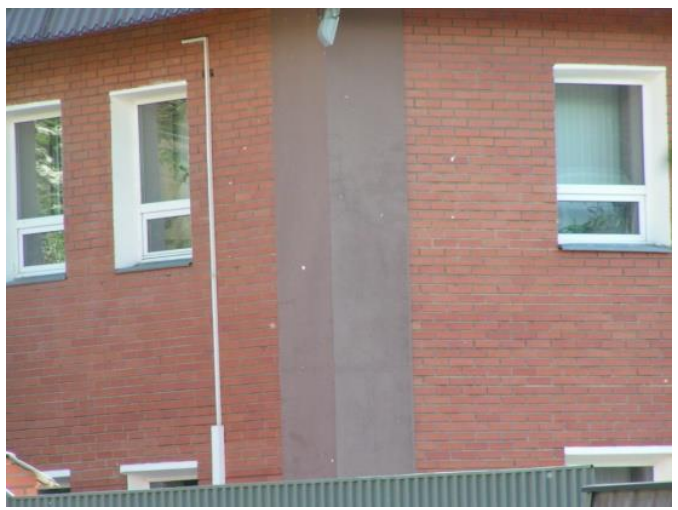

b)For corner sites with the location of vertical cracks at a distance of $50 \ldots 60 \mathrm{~cm}$ from the corner of the building

Fig. 8. Schematic diagram of the plaster layer on the corners of the repaired building (a) and one of the repaired corners (b).

9. According to the performed calculations, the device of temperature expansion joints is recommended on each of the walls of the building. Such a number of seams reduces stress in the corner areas of the facing layer. The seam is cut through the entire thickness of the facing brick, is sealed with a sealing gasket and sealed according to the scheme shown in (Fig. 9,10). 


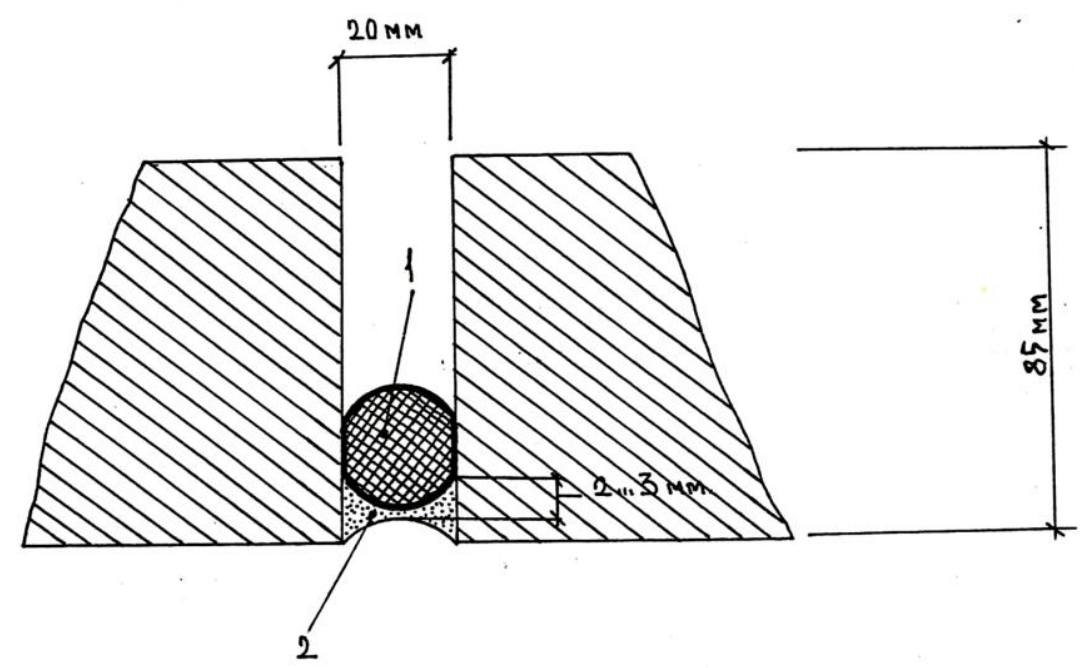

Fig. 9. Deformation seam device by using a sealant (1) and sealing mastic (2).

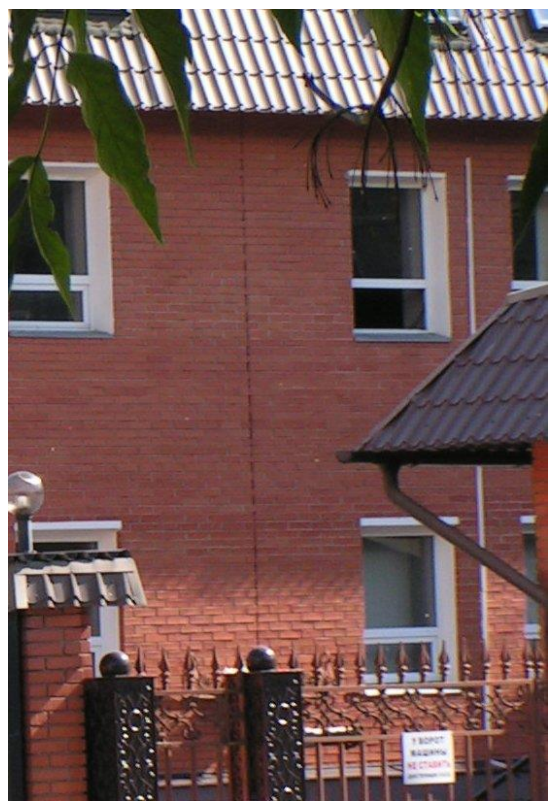

Fig. 10. Deformation seam on the brickwork of the facing layer.

\section{Discussion}

The main problem. Which faced the administration, was that the masonry of the facing layer of the building began to flake off the main masonry and bend over. Vertical and horizontal trunk cracks began to appear on the surface of the lining. This became noticeable to the unaided eye and threatened to collapse. There was a danger for workers working in the factory along the walls of the building. The reason for this phenomenon was incomprehensible, as a result of which research work was carried out. A comprehensive survey showed that the laying of the main walls of a building made of full-bodied ceramic 
bricks $51 \mathrm{~cm}$ thick was first erected without facing, and the lining was completed only after two years. To fix and connect the facing layer with the main masonry of the outer walls, a masonry net was laid in it during the production process, the outlets of which were to be included in the masonry of the facing layer. As a result of inspection of opened window slopes, it is established that the mesh protruding from the main masonry does not enter the seams of the cladding, but is bent into the gap. Consequently, the facing layer of masonry, which is devoid of connection with the main wall, works independently as a self-supporting wall $85 \mathrm{~mm}$ thick. And a height of $6000 \mathrm{~mm}$

In view of the fact that the laying of the main walls was carried out with vertical deviations, the gap between the facing layer and the main laying is variable from 1.5 to 5 $\mathrm{cm}$, the gap was not filled specifically with the solution, and there are separate random inclusions.

To support the facing layer from the bottom of the wall, there is a socle wall made of full-bodied ceramic bricks, $25 \mathrm{~cm}$ wide and 60 to $95 \mathrm{~cm}$ high. This wall could not be placed on the edge of the foundation blocks with a width of $60 \mathrm{~cm}$ and the width of the main wall $51 \ldots 52 \mathrm{~cm}$. Therefore, to support the socle wall along the ground, a horizontally located monolithic reinforced concrete beam section $30 \times 30 \mathrm{~cm}$ was concreted. The nature of the reinforcement of this beam is not established.

Of the causes that caused the formation of cracks in the facing, two are distinguished: $=$ Horizontal cracks:

1. The stressed state of the facing layer when it is subjected to a vertical load from its own weight in the presence of eccentricity due to the deviation of the facing from the vertical with insufficient number of flexible connections between the lining and the main wall;

2. Vertical deposit of the socle wall on which the lining rests under the deflections of the reinforced concrete contour beam erected along the loose ground; $=$ Vertical cracks:

3. The tensed state of the facing layer when working on compression from its own weight, as a sign of overstrain of the mas 4 . The uneven draft of the basement wall with a supporting contour reinforced concrete beam;

5. Efforts of the horizontal direction caused by temperature deformation of the facing layer, insulated from the main masonry by an air gap and having insufficient number of flexible connections with the main wall.

To assess the stressed state of the facing laying, working on eccentric compression, the actual value of the eccentricity of the vertical force from the own weight of the masonry was determined. The value of the eccentricity is calculated from the results of the measurements of the deviation of the facing from the vertical position by scanning around the perimeter of the entire building in steps of two meters.

A general analysis of the results of the survey made it possible to calculate and determine measures to stabilize the situation and prevent the collapse of the object.

\section{Conclusions}

1. Between the surface of the main wall and the facing brick layer there is a gap of $1.5 \ldots$ $5.0 \mathrm{~cm}$ and a deviation of the facing layer from the vertical surface to $3.5 \mathrm{~cm}$.

2. The opening of window slopes established that the mesh, protruding from the main masonry, does not enter the seams of the cladding, but is bent into the gap. Therefore, the facing layer of masonry, which is devoid of connection with the main wall, operates independently as a self-supporting wall.

3. It is recommended to fix the cladding layer to the masonry of the main wall with steel ties. Holes for bonds $\varphi 20 \mathrm{~mm}$. Drilled by an electrified tool. The links are staggered in 
steps of $50 \ldots 80 \mathrm{~cm}$ from the rods of $\mathrm{f} 10 \ldots 12 \mathrm{~mm}$. Periodic profile, the length of $35 \ldots 40$ $\mathrm{cm}$ at an angle of 300 .

4. In 7 days after installation of connections it is recommended to insert gaps between the laying of the main wall and facing with cement-sand paste of the same composition as for steel ties. For injection, one hole is recommended for an area located between two ties and reamed to the depth of the facing brick, that is $85 \mathrm{~mm}$. Fastening of the cladding should be made by grippers of a width of $5 \mathrm{~m}$ and a height of no more than $2 \mathrm{~m}$.

5. It is ascertained that on the surface of the facing brick at a distance of up to $60 \mathrm{~cm}$ from the corners vertical vertical vertical cracks were found with the opening $1.5 \quad \ldots 2.0$ $\mathrm{mm}$. To preserve the decorative texture of the brick and eliminate vertical cracks, it is proposed to make a plaster coating from a cement-sand mortar $30 \mathrm{~mm}$ thick at the corners of the building. On a metal grid of $\varphi 4 \mathrm{~mm}$. With a cell $50 \times 50 \mathrm{~mm}$. After the solution is hardened, the surface is puttyed and painted.

6. According to the performed calculations, the device of temperature expansion joints is recommended on each of the walls of the building. Such a number of seams reduces stress in the corner areas of the facing layer. The seam is cut through the entire thickness of the facing brick, embroidered with a sealing gasket and sealed.

\section{References}

1. Russian Standard SP 13-102-2003

2. I.A. Rybiev, Construction Materials Science (Higher School Publishing House, Moscow, 2003)

3. A.I. Bedov, A.I. Gabitov, Design, restoration and reinforcement of stone and reinforced-stone structures (ASV, 2006)

4. Russian Standard GOST 31937-2011

5. V.G. Mikulsky, G.P. Sakharov, Construction materials. Materials Science. Technology of constructional materials, textbook for universities (Publishing House of the DIA, Moscow, 2011)

6. Yu.M. Bazhenov, Technology of concrete, textbook for university students studying in building specialties (ASV, Moscow, 2011)

7. Russian Standard GOST 25192-2012

8. Russian Standard GOST 22690-2015

9. Russian Standard GOST 18105-2010

10. Russian Standard SP 20.13330.2011

11. V.P. Kamskov, R.F. Serova, E.A. Stasilovich, Vestnik of modern science 12-1(12), 3943 (2015)

12. G.M. Rakhimova, G.A. Seydinova, Scientific journal Fundamental research 11(5), 1220-1223 (2012)

13. B.M. Rumyantsev, Systems of insulation of building structures, textbook (MSSU, Moscow, 2013)

14. V.P. Kamskov, V.V. Kozlov, Waterproofing materials, Scientific publication Moscow (2014)

15. V.E. Bayer, Architectural Materials Science, textbook for high schools (Architecture-S, Moscow, 2012)

16. N.V. Treskov, Technology of insulating and finishing materials and products. Part 1. Technology of heat-insulating materials, a tutorial (EBS DIA, Moscow, 2014) 
17. V.P. Kamskov, I.V. Balandina, D.Yu. Zemlyanushnov, Modern trends in the development of science and technology 9-3, 95-99 (2015)

18. A.N. Grishina, E.V. Korolev, Liquid-glass building materials of special purpose (Monograph-Moscow, Moscow, 2015) 